\title{
Ecosystem-Based Management and Natural Capital Accounting
}

\author{
Marc Russell, Charles Rhodes, George Van Houtven, Paramita Sinha, \\ Katherine Warnell, and Matthew C. Harwell
}

\begin{abstract}
Natural capital includes the physical and biophysical components of an ecosystem working together to produce a flow of services to the economy and to society that support human well-being. An ecosystem service thus represents a type of transaction between natural capital and humans and can be considered within tools to support Ecosystem-Based Management (EBM) decision making. A natural capital perspective can be a useful way to put the value of ecosystems on par with other socioeconomic values in an EBM decision context. Further, the application of structured classifications for ecosystem components, human beneficiaries (users), and a suite of flows of final ecosystem services helps EBM practitioners organize information for a given decision context. This chapter explores the utility of natural capital accounting as a tool for EBM, outlines a standardized framework for natural capital accounting, and summarizes an ecosystem services classification system for natural capital accounting that can be used as an EBM tool, especially relevant for the decision-making step of evaluating management options (e.g., scenarios).
\end{abstract}

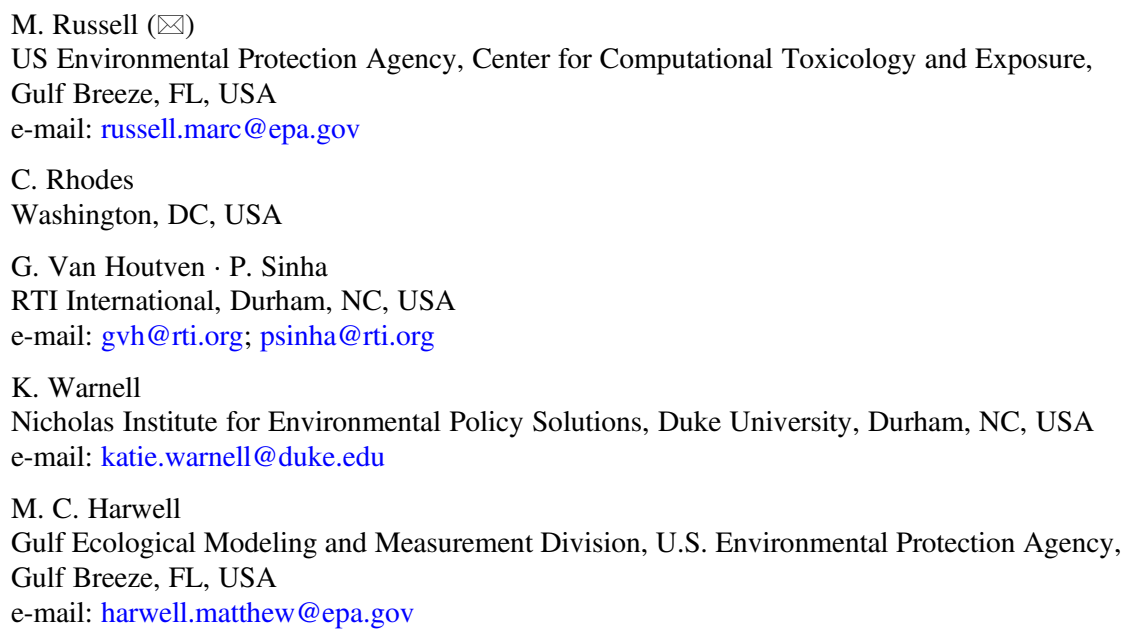




\section{Lessons Learned}

- The organizational structure of the National Ecosystem Services Classification System (NESCS) allows for the determination of environmental and valuation measures and metrics using classes and sub-classes specific enough that they minimize the possibility of double counting specific ecosystem service flows, an important criterion for establishing the creditability of ecosystem services assessments.

- The format of a NESCS code is WW.XX.YY.ZZZ, where each set of digits refers to the Environment, Ecological End-product, Direct Use/Non-use, and Direct User classes and subclasses, a useful feature for aggregating items in natural capital accounting tables, representing a unique potential pathway through which changes in Natural Capital may affect human welfare.

- Natural capital accounting efforts are directly relevant to the structured decisionmaking step "Estimate Consequences" in answering the question, "What ecosystem services models or data are needed to estimate consequences?"

- Natural capital accounting helps EBM practitioners organize: information for a given decision context; ways to approach the identification and valuation of the final ecosystem services for EBM decision making, especially relevant for evaluating management options (e.g., scenarios); and the standardized tracking of specific final ecosystem services over time.

\section{Needs to Advance EBM}

- As a new potential tool in the EBM toolbox, EBM practitioners need to examine natural capital accounting principles as part of efforts to analyze different scenario options as part of a decision context.

- Several natural capital accounting approaches (e.g., NESCS and InVEST) could be applied to the same decision context to inform the value-added benefits of natural capital accounting in EBM decisions.

\section{Introduction}

Management of ecosystems is a complicated affair (Delacámara et al. 2020). Not only do managers have to consider the many interactions in the ecology of a system, they are also mandated to manage the system for human-established goals. These goals might be conservation or restoration focused and oriented for ecological health and integrity or designated uses by humans. In either case the manager needs a way to break down a system into its component parts, quantify them in some way, link those parts to management goals, and assess trends over time, so they can adapt their management accordingly (Arkema et al. 2006; Guerry et al. 2015). Since physical structures, plants, and animals are easier to track than functions or processes, managers often rely on quantification of habitats, species, and abiotic factors monitored on a reoccurring basis. These factors can be thought of as natural capital (Costanza et al. 1997; Millennium Ecosystem Assessment 2005). 
Natural capital is the physical components of an ecosystem working together to produce something of value to people (Costanza and Daly 1992). Ecosystem-based managers are focused on natural capital and on what that capital produces in their jurisdiction. Natural capital, just like typical economic capital, can be thought of as the machinery or structures that function to produce goods. In the case of natural capital, these goods are biophysical components that, when used or appreciated by humans, produce a flow of services to the economy and to society more generally, thereby supporting human well-being. Natural capital might act alone or may interact with other natural capital in a series of production functions-relationships between one feature of the environment and the production of another-to produce that which is directly valued, used, or otherwise consumed by humans. That biophysical component of nature that is used directly by humans has been referred to as a final ecosystem good (Landers and Nahlik 2013; DeWitt et al. 2020) or an ecological end-product (Boyd and Banzhaf 2007; Finisdore et al. 2019). These terms denote that the useful biophysical component is a result of production by natural capital. The Ecosystem Service (sometimes referred to as an ES in the literature) then represents a type of transaction between natural capital and humans. At that point, the Final Ecosystem Service (sometimes referred to as FES in the literature) is a transaction that adds value to economic production processes (which generate economic goods and services), or that directly contributes to human wellbeing (such as from the inspiration provided by a natural landscape).

Value is placed on the flow of ecosystem services produced when humans interact with ecosystems, as natural capital, through their use or appreciation of a final ecosystem good or ecological end-product (Farber et al. 2002). A natural capital perspective of ecosystems may help managers align ecological production and resulting flows of ecosystem services in a way that best supports or enhances human well-being. This chapter explores elements of natural capital, a standardized framework for natural capital accounting, ecosystem services classification in natural capital accounting, and the use of natural capital accounting as a tool for EcosystemBased Management (EBM).

\section{Elements of Natural Capital}

A natural capital perspective lends itself to the application of already accepted socioeconomic frameworks, tools, and approaches, and thus can be a useful way to put the value of ecosystems on par with other socioeconomic values in the system being managed (Wackernagel et al. 1999; Hein et al. 2016). An accounting framework, for example, can be applied to natural capital production to help differentiate what and how things produced by ecosystems are used, by whom, and whether supply is being maintained at levels that satisfy demand. Natural capital accounting is practiced by several countries to quantify and track natural resources such as in water (e.g., Hoekstra 2009), minerals (e.g., Lange 2004), and land accounts (e.g., Weber 2007). Specific ecological production in ecosystems is also being tracked using timber (e.g., Gundimeda et al. 2007), fisheries (e.g., Lange 2004), and wildlife 
accounts (e.g., Anderson 2003). These accounts have been called for by countries and regions experiencing scarcities, such as in droughts, or in areas that rely heavily on natural resources as the base of their economies. They are becoming more commonplace as the World Bank and the United Nations call for more standardized practices of ecosystem reporting and management (United Nations 2014). A natural capital accounting framework also allows one to tie ecosystem production to the economy by providing the structure to quantify biophysical supply and use by specific ecosystems and users, thereby providing the information needed for valuation and possible translation of that biophysical use into monetary terms (Guerry et al. 2015).

Natural capital accounting requires three types of classifications to work together. First, a list of ecosystems, natural areas, or other geographic groupings that separate out the various production areas with no overlapping areas is needed to cross reference to ecosystem production or supply from natural capital located within the boundaries of the area. Second, the supply from natural capital in the system needs to be apportioned to a list of users. Common to both the supply and use tables within an account, and tying them together, are the various ecosystem services. The quantified ecosystem goods, or ecological end-products (sometimes referred to as EEP in the literature), and their use by users (beneficiaries) for a given time period of a given natural capital account serves as the measure or count of ecosystem service flows that will populate the table cells. Within an accounting framework, for the accounts to balance, the total supply from ecosystems must equal the use by users. It is the list of these ecosystem goods or ecological end-products that is the third type of classification that is needed to construct natural capital accounts.

\section{Standard Framework for Natural Capital Accounting}

A standard framework for natural capital accounting called the System of Environmental-Economic Accounting, or SEEA, has been developed by the United Nations and partner organizations (Hein et al. 2016). Tangible environmental assets including land, water, minerals, and several resources such as timber and fish are part of the Central Framework, which makes up the core of SEEA, and is designed to quantify natural resources and their contributions to the economy in biophysical and monetary terms (United Nations 2014). The SEEA also houses Experimental Ecosystem Accounts (SEEA-EEA) which are tasked with tracking the extent and condition of ecosystem assets (ecosystems represented by spatial areas; e.g., forests, wetlands, cropland) and the flows of various ecosystem services that these ecosystem assets provide to people and the economy (United Nations 2014). These Experimental Ecosystem Accounts are needed to account for flows from complex ecosystems to people, flows that have not been treated in national accounts as natural resources and traded as commodities in the market. Ecosystem service flows in the Experimental Ecosystem Accounts are by nature difficult to translate into monetary contributions to the economy, as is done with the environmental assets of the Central Framework.

The SEEA-EEA definitions are laborious, detailed, and undergoing updates through 2020, but were constructed with extreme care to meet national accounting 
needs. Ecosystem assets are a type of capital, similar to machines in a factory, and yield a flow of ecosystem services, just as the factory machines yield a flow of services (e.g., they might stamp thick metal sheets into useful shapes faster and more accurately than humans with hammers could). The SEEA-EEA ecosystem services are "final" as in the definition in Boyd and Banzhaf (2007), and can be distinct from "benefits," where benefits may be the FES contribution to economic production or the FES may go directly to the users without further economic processing or inputs.

Within the SEEA-EEA framework of accounts, figures proposed as frames for "ecosystem services supply and use tables" list "ecosystem services" as rows in the supply-and-use tables (Fig. 1). The supply tables connect ecosystem services and products (in rows) to the types of assets that produce them (in columns) while the use tables connect them to the types of users that use them (in columns). The dark shaded shells in these tables represent "null sets" meaning that no supply or use connection exists for that row-column combination.

Ecosystem services supply-and-use tables are required to balance in accounting. This means that supply of an ecological end-product cannot be larger or smaller than the amount of that ecological end-product used in ecosystem service transactions, nor can it be missing for an ecosystem service to exist. In accounting, a supply with no use cannot represent an ecosystem service because there is no balancing entry in the corresponding use table. A nation cannot have $1000 \mathrm{~km}$ of swimmable shoreline and use only $100 \mathrm{~km}$ of it in the same accounting year and be able to correctly say they had more than $100 \mathrm{~km}$ of shoreline supplied and used as an ecological end-product within an ecosystem service. By the strictures of accounting, the other $900 \mathrm{~km}$ cannot be counted as an ecological end-product or part of a flow of ecosystem services during that year, because they were not used. Rows with no entries thus cannot represent ecological end-products, because the existence of transactions (depicted with entries in the intersecting cells) verifies final use, linking supply and demand within the flow of an ecosystem service. The numbers in the cells are a way to quantify particular ecosystem services as a transaction or flow between the supplying ecosystem asset and the human user.

Without use, there is not an ecosystem service, and thus proposed ecological end-products that ultimately do not have direct human use or appreciation (e.g., a wolf or eagle that lives and dies hundreds of miles from any human, say in remote reaches of Alaska, and is not valued specifically for its existence or bequest value) should not be included in accounting supply-and-use tables. Nonuse values are harder to derive in a transaction-value-based framework, which the SEEA is, so are currently not allowed. However, those same wolves or eagles not directly used might still be counted in another type of EEA account other than the supply-and-use tables, perhaps reflecting the condition of a distant ecosystem asset in a condition table or providing a service only between ecosystem assets. Thus, it is critical to define ecosystem services with a use and user component, and not just by identifying potential supply. Ecosystem services classification systems before those developed by the USEPA may have presumed, but did not directly incorporate, a use/user component. Without actual use, things classified as part of an ecosystem service are just ecosystem characteristics and processes that cycle through the environment, and thus not ecological end-products or part of final ecosystem services. 

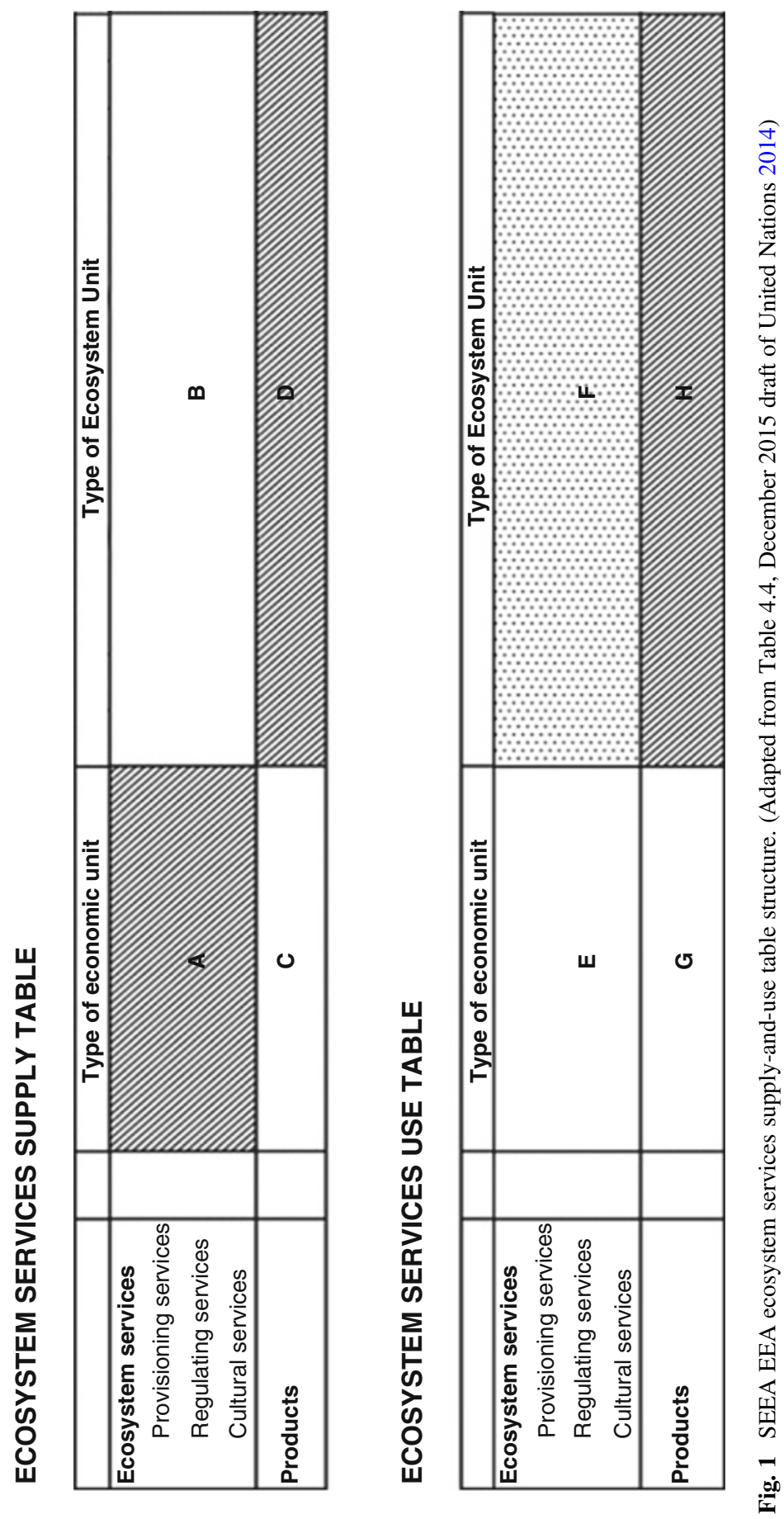
The U.S. natural capital accounting workgroup (Warnell et al. 2020) recognized the narrowness of the accounting definition and the difficulty of measuring actual ecosystem services and put important ecological measures and measures of known precursors of ecosystem services into an ecosystem condition account. For example, eagles and beaches that humans do not interact with might be tracked in a condition account. Accounts that are balanced, totaled, and specifically slated for integration with Standard National Accounts (SNA, the international accounting structure that provides a common economic foundation before environmental accounting is applied) need to have safeguards against double-counting. The supply-and-use tables are intended to be monetized and to be integrated with the SNA accounts in common terms. Condition accounts are not currently proposed to be integrated into the SNA or to be translated into dollar values, so can represent characteristics, processes and stocks of things (e.g., eagles) in the environment that are not directly used as part of ecosystem services.

\section{Classification of Flows of Ecosystem Services for Natural Capital Accounting}

The US EPA's National Ecosystem Services Classification System (NESCS) offers all three of the classification elements (i.e., types of supplying ecosystems, types of ecological end-products supplied and used, and types of users with different use demands) that are needed to do natural capital accounting (USEPA 2015). The NESCS and associated approach were designed to help identify and reference flows of services from ecosystems to human beings in a mutually exclusive way, which is critical for natural capital accounting.

The NESCS has a four-part structure (Fig. 2), with each part populated by a hierarchical set of classes and subclasses, which are intended to be as non-overlapping and comprehensive as possible for identifying distinct ecosystem service flows.

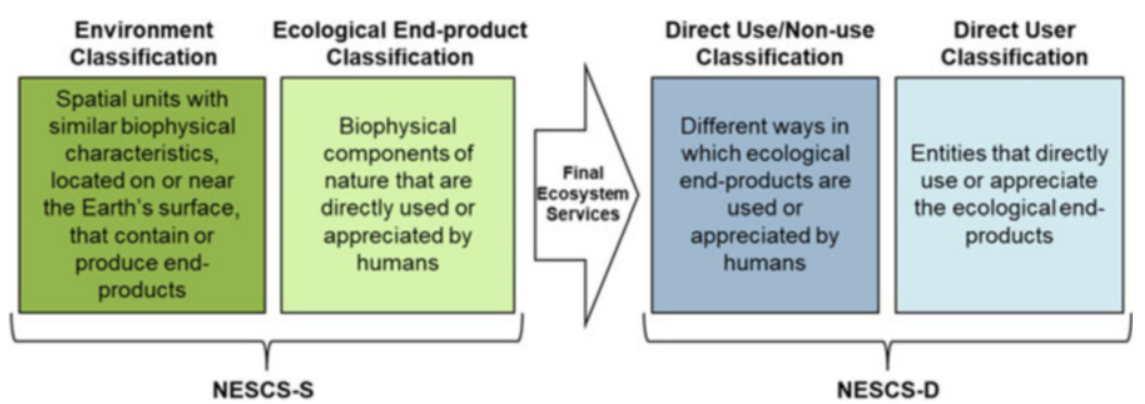

Fig. 2 NESCS four-part structure (from USEPA 2015) 
The four parts of NESCS can be divided into two sides that are relevant for accounting: the supply-side (NESCS-S; Fig. 2 left) and demand-side (NESCS-D; Fig. 2 right) of the system. The NESCS-S side represents the source of ecosystem service flows. It characterizes different types of natural capital as environmental classes and represents the output of their ecological production as classes of ecological end-products. The NESCS-D side represents the recipients of the ecosystem service flows, by classifying the human users of the ecological end-products and how they are used. Taken together, the four parts hold the information necessary to designate individual flows of ecosystem services from natural capital to humans.

The NESCS adopts a nested hierarchical structure so that each part can be represented at multiple levels of aggregation or detail. The initial sets of classes presented by NESCS are meant to provide a high-level classification that provides a mutually exclusive partitioning of classes, each with its own set of subclasses. These initial classes and hierarchical structure were developed to meet the design requirements not found in other classification systems. The NESCS is intended to provide a broad and comprehensive structure capable of covering all the different ecosystem services that humans value from nature. In this regard, it is consistent with the total economic valuation (TEV) approach (e.g., Jewhurst and Mazzotta 2016) that is often used as a framework for valuing natural resources and environmental benefits. The NESCS is also expandable enough to identify specific classes and subclasses for determining environmental and valuation measures and metrics. It has classes that are intuitively separate from each other and thus specific enough that, when combined to represent flows of ecosystem services, they minimize the possibility of double counting specific ecosystem service flows, an important criterion for establishing the creditability of ecosystem services assessments ( $\mathrm{Fu}$ et al. 2011). Moreover, by focusing on ecosystem services and the ecological end-products produced by natural systems, the NESCS structure also minimizes the possibility of double counting the contribution of "intermediate" ecological production processes in estimates of ecosystem service values (Landers et al. 2016). This is because the value of intermediate processes should be embedded within, and thus fully captured by, the value of final ecosystem services.

Each unique ecosystem service can also be easily referenced and identified by a NESCS code. The general format of the code is WW.XX.YY.ZZZ, where each set of digits (e.g., WW, XX, etc.) refer to the Environment, Ecological End-product, Direct Use/Non-use and Direct User classes and subclasses, respectively, as described below (Fig. 3). One example from Fig. 3, the WW.XX.YY.ZZZ NESCS code "41.12.11.2ZZ" would thus represent household extractive use of liquid water from a deciduous forest, as for a hiker taking a drink of water from a mountain stream below the tree line. Digits can be added or removed from each part of the four-part code to represent any further breakdown into more detailed sub-classes or to represent the roll up of subclasses into larger classes. While the ability to roll up classes into fewer classes is a useful feature for aggregating items in natural capital accounting tables, it may be less so for other uses of NESCS not covered here, such as the identification of metrics for each Flow of Ecosystem Service, mapping of areas of supply, or setting up scenario variables, which would primarily take advantage of 


\section{NESCS Four-Part Coding Examples (WW.XX.YY.ZZZ)}

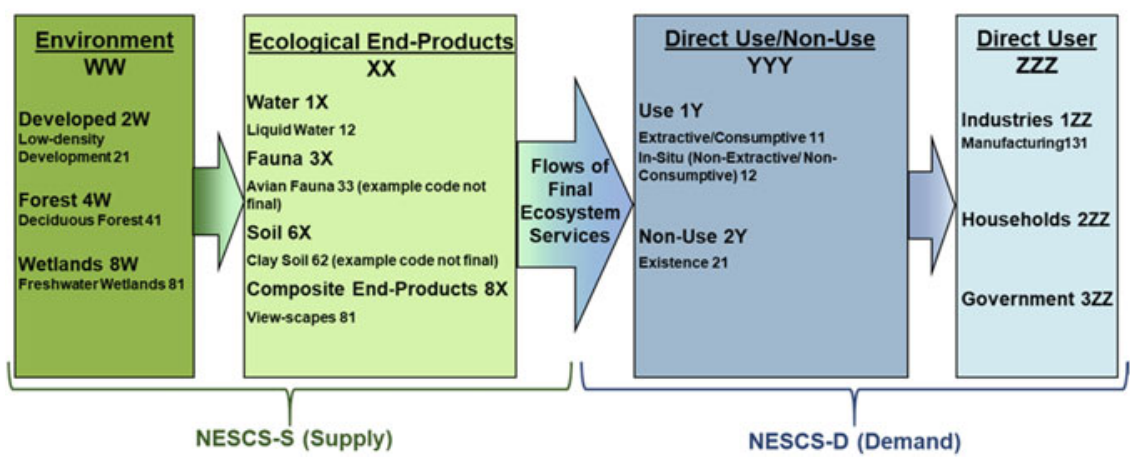

Fig. 3 NESCS coding examples (WW.XX.YY.ZZZ)

the flexible yet comprehensive nature of the hierarchical classification system. Each unique combination of one class or subclass from each of the four parts of NESCS defines a separate Flow of Ecosystem Service. In other words, it represents a unique potential pathway through which changes in Natural Capital may affect human welfare. The ability to define different combinations of classes allows the NESCS structure to be flexible and comprehensive. For example, the same Ecological End-Product category may be used in multiple ways or a single use category can be linked to multiple different user categories.

The first part of NESCS is the Environment classification (Fig. 3; far left box; "WW" part of the code), which is currently based on the system specified by Landers and Nahlik (2013). It spatially divides the Earth into non-overlapping areas with similar biophysical characteristics that, when taken together, can completely cover the surface of the Earth. The NESCS currently designates Environment classes down to a second-level of hierarchy, including a two-digit numeric coding structure, which provides a short-hand notation for the hierarchy and a numeric identifier for each element within each part. Example subclasses for the environment might include deciduous forests, freshwater wetlands, or low-density developments. When used within a four-part code designating a final ecosystem service, the environment classes and subclasses specifically refer to the environment in which the relevant ecological end-product is used or appreciated.

The second part of NESCS is the Ecological End-products classification (Fig. 3; second to left box; "XX" part of the code). End-products represent the components in nature that humans most directly use or appreciate (Farber et al. 2002). In its most aggregate form, classes of ecological end-products include Fauna, Flora, Water, Soil, Air, etc. As with Environment classes, these are subsequently broken down into a second-level hierarchy of subclasses, with codes designated for each one. Examples might include liquid water, avian fauna, or clay soils. One of the challenges in constructing this end-product classification is defining mutually exclusive categories while also recognizing that there can be substantial complexity and diversity in what 
people care about in nature. In addition to individual end-products, people often care about combinations of them. For example, people may value an entire landscape as more than the sum of individual value for the flora, fauna, water, etc., that are parts of the landscape. The NESCS includes a category called "Composite End-products" with sub-classes representing different types of natural features or phenomena that directly matter to humans but can be thought of as combinations of the other end-products. An example might be view-scapes. It is important to recognize that the joint nature of composite end-products may be problematic when applied to an accounting framework where there can be no overlaps between entries in the supplyand-use tables.

The third part of NESCS is the Direct Use/Non-Use classification (Fig. 3; second to right box; "YY" part of the code). The classes and sub-classes in this component describe distinct ways in which end-products can be directly used or appreciated by humans, again with the objective of providing categories that are non-overlapping and as comprehensive as possible. Examples include extraction of natural resources, such as wood, for transformation into economic products, such as timber, or non-extractive in-situ use associated with outdoor recreation, such as birdwatching. Consistent with the TEV framework, it includes separate "use" and "non-use" categories which make up the first hierarchical level. These use and non-use classes are then further subdivided into mutually exclusive extractive and in-situ use classes at the second-level of the hierarchy. Non-use use classes include existence, bequest, or other uses where humans do not have direct contact or physical use of the ecological end-product but might have a value associated with knowing that something exists or that something will be around for their descendants to enjoy.

The fourth and last NESCS part is the Direct User classification (Fig. 3; far right box; "ZZZ" part of the code). This component defines the separate economic sectors though which people directly use or appreciate end-products. Following established classification structures adopted by the U.S. Census Bureau and United Nations, the first level includes broad sectors of the economy, here: Industry, Households, and Government. To further subdivide the industry class, it adopts the existing North American Industrial Classification System (NAICS) and coding system, which is the standard used by U.S. federal statistical agencies in classifying business establishments (United States 2017). An example is the Manufacturing Industry sector which has a three-digit code, one digit for industry and two additional digits for the sector. Unlike commercial establishments, which tend to specialize in certain productive activities and can therefore be assigned to individual NAICS categories, households and governments do not specialize in the same way. For this reason, they are not yet divided into sub-classes as are NAICS categories. They currently are presented as first-level hierarchical classes, with further designation to subclasses remaining an option. One way to differentiate the many ways households and governments interact with nature is through the combination of the household or government user class with the different previously described use/non-use classes.

The NESCS approach helps guide the construction of supply-and-use tables within SEEA-EEA in that it clearly separates ecological end-products from ecosystem services by defining ecological end-products (i.e., components in nature that 
humans most directly use or appreciate) as part of a flow of ecosystem services (i.e., "transactions" that include human use of those components by a specific user). Without this specificity in terminology, confusion of, and mismatches between, what ecologists and other natural scientists measure as that which is supplied by an ecosystem asset and what social scientists measure as that which is used by a user could slow or stall efforts to generate useful estimates of ES for accounting.

The NESCS identifies and classifies components of final ecosystem services according to both the environmental supplier and human user of the service in order to identify where certain metrics best fit within the natural capital accounting structure (Fig. 4a). The NESCS can help distinguish between ecosystem services eligible for inclusion in supply-and-use accounts in standard statistical frameworks, such as SEEA-EEA. By viewing the standard statistical frameworks through the NESCS lens, one can separate ecosystem characteristics and processes that some have considered to be ecosystem services from those ecosystem services that are allowable by the structure of supply-and-use accounting (finality in accounting is proven by direct use; Boyd and Banzhaf 2007; Landers and Nahlik 2013; Landers et al. 2016; USEPA 2015; United Nations et al. 2017). The NESCS offers a practical and flexible structure and set of rules for naming ecosystem service flows as the central object of measure in the supply-and-use account.

Using the four component NESCS classification, "ecological end-products" may be a more functional label for types of SEES-EEA supply and use table row names than the label "ecosystem services." (Fig. 4b) Whether the rows in a SEEA-EEA supply-and-use table are named ecological end-products or ecosystem services however, cells in the rows sit at the intersection with columns that either designate supply of an ecological end-product by an ecosystem asset, or designate use of an ecological end-product by a particular user. Since an ecosystem service can be thought of as a transaction between nature and humans, row names must match in both the supply-and-use tables since an individual cell represents the common interaction point, or transaction (i.e., ecosystem service), between the two tables. For any one ecosystem service type defined by ecosystem assets, ecological end-products and types of (use and) users, supply must match demand for the account to balance. Quantities in cells within EEA supply and use tables should, thus, be measures of ecosystem services in that they simultaneously represent both the supply and use of a particular ecological end-product (i.e., the row).

\section{Natural Capital Accounts as Tools for Ecosystem-Based Management (EBM)}

Frameworks and approaches to develop ecosystem services classification and accounting systems focus on developing common, shared language and consistent approaches for identifying, assessing, and accounting of ecosystem goods and services for specific human benefits (DeWitt et al. 2020). These approaches are 

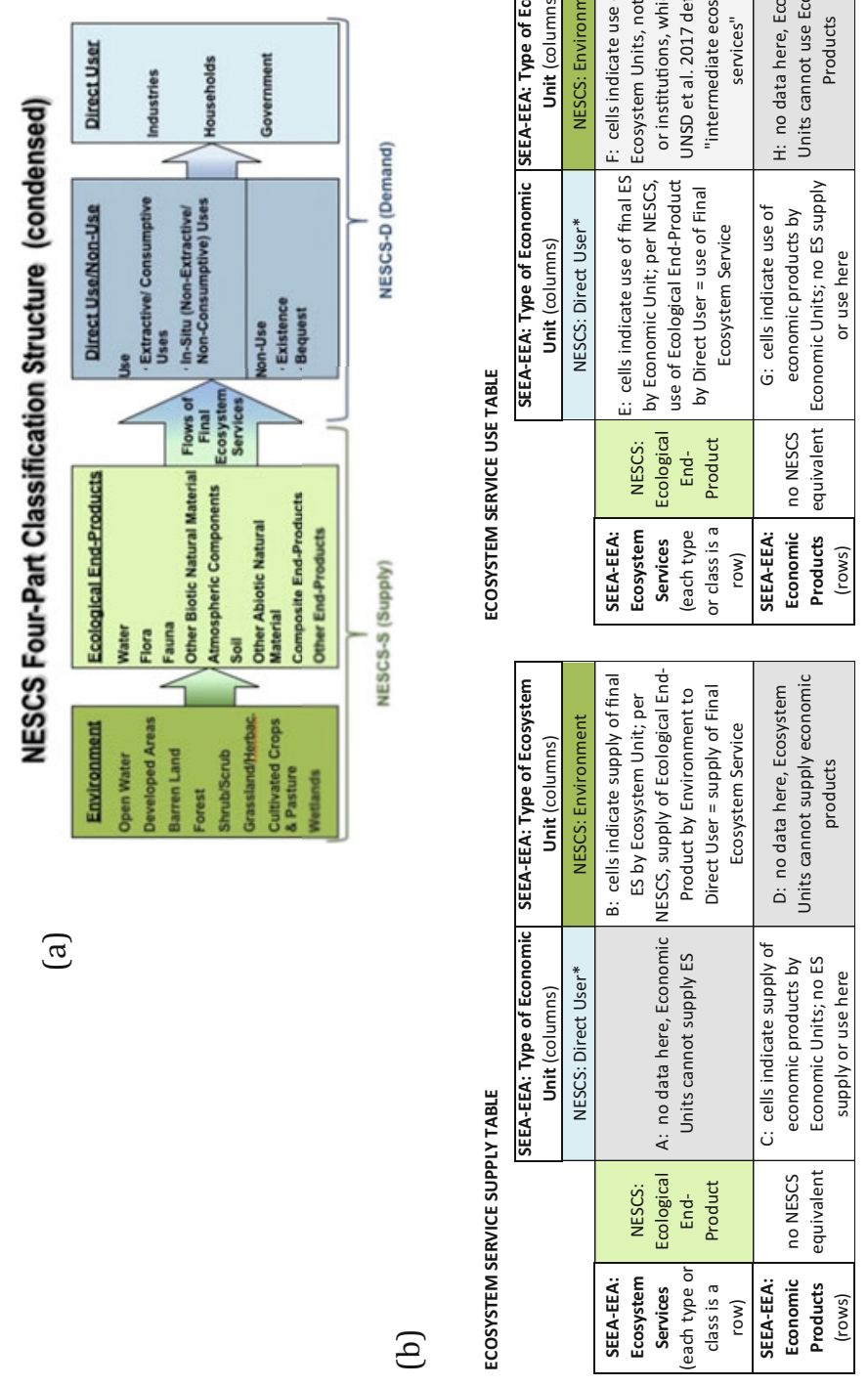

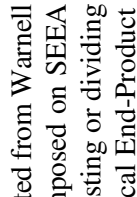

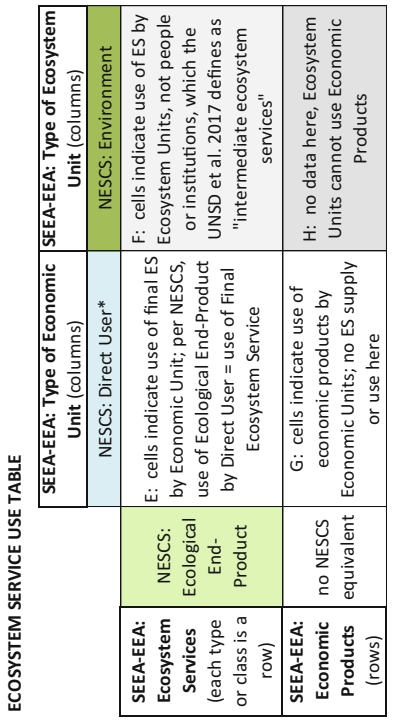

帚苛可

这灾

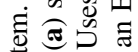

के

ธ월

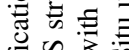

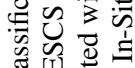

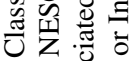

记

的

으름ำ

可苋

市矛㝴

记公空

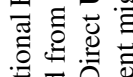

壳芯芯

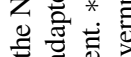

导过

苛些

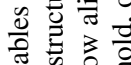

敋

范密至

증ํำ

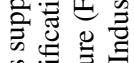

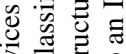

च

क्षे

क

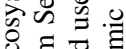

\& छ

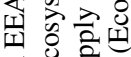

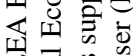

떤 ज] के

㻤.

ङ

50.

दत् ठิ

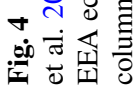


designed to be used primarily by scientists but developed to be useful for resource managers and ecosystem-based management practitioners. DeWitt et al. (2020) presents a crosswalk examining ecosystem services from a structured decisionmaking perspective with assorted EBM frameworks, including AQUACROSS (Piet et al. 2017; Delacámara et al. 2020). Natural capital accounting efforts are directly relevant to the structured decision-making step "Estimate Consequences" in answering the question: "What ecosystem services models or data are needed to estimate consequences?" This is translatable to Step 4 in the AQUACROSS framework, "Implementation, Monitoring and Evaluation," which focuses on either assessment of current state, or the application of forecasting and scenario tools to examine/predict consequences among alternative management decisions. This potential application of natural capital accounting also maps onto the step of "Evaluating Management Measures" (Cormier et al. 2017) and "Scenarios" (Foley et al. 2013) in other EBM frameworks. The InVEST (Integrated Valuation of Ecosystem Services and Tradeoffs) is one example of a modeling approach to utilize natural capital accounting for decision-making purposes (Daily et al. 2009); for further discussion on InVEST in this volume, the reader is directed to Fulford et al. (2020) and Lewis et al. (2020).

Overall, the natural capital accounting framework provides several important tools for EBM practitioners. First, the application of structured classifications for ecosystem components, human beneficiaries (users), and a suite of flows of final ecosystem services helps EBM practitioners organize information for a given decision context. Second, a natural capital accounting framework perspective informs the effort to identify and value the final ecosystem services for EBM decision making and to track them over time in a standardized way. Finally, the structured nature of natural capital accounting frameworks lends itself to supporting important EBM steps focused on evaluating management options among a suite of EBM alternatives for a given decision context (sensu DeWitt et al. 2020). With this perspective, EBM practitioners are encouraged to learn more about natural capital accounting in general, the meticulously detailed organization of the United Nation's SEEA-EEA (United Nations 2014), and the U.S. EPA's approach to natural capital accounting using NESCS (USEPA 2015), so they might add these tools to their EBM toolbox.

Disclaimer This chapter has been subjected to Agency review and has been approved for publication. The views expressed in this paper are those of the author(s) and do not necessarily reflect the views or policies of the U.S. Environmental Protection Agency.

\section{References}

Anderson, H. J. (2003). An econometric analysis of the wildlife market in South Africa. Dissertation, University of Cape Town.

Arkema, K. K., Abramson, S. C., \& Dewsbury, B. M. (2006). Marine ecosystem-based management: From characterization to implementation. Frontiers in Ecology and the Environment, 4 (10), 525-532. 
Boyd, J. W., \& Banzhaf, S. (2007). What are ecosystem services? The need for standardized environmental accounting units. Ecological Economics, 63, 616-626.

Cormier, R., Kelble, C. R., Anderson, M. R., Allen, J. I., Grehan, A., \& Gregersen, O. (2017). Moving from ecosystem-based policy objectives to operational implementation of ecosystembased management measures. ICES Journal of Marine Science, 74, 406-413.

Costanza, R., \& Daly, H. E. (1992). Natural capital and sustainable development. Conservation Biology, 6(1), 37-46.

Costanza, C., d'Arge, R., de Groot, R., Farber, S., Grasso, M., Hannon, B., Limburg, K., Naeem, S., O'Neill, R. V., Paruelo, J., Raskin, R. G., Sutton, P., \& van den Belt, M. (1997). The value of the world's ecosystem services and natural capital. Nature, 387, 253-260.

Daily, G. C., Polasky, S., Goldstein, J., Kareiva, P. M., Mooney, H. A., Pejchar, L., Ricketts, T. H., Salzman, J., \& Shallenberger, R. (2009). Ecosystem services in decision making: Time to deliver. Frontiers in Ecology and the Environment, 7(1), 21-28.

Delacámara, G., O'Higgins, T., Lago, M., \& Langhans, S. (2020). Ecosystem-based management: moving from concept to practice. In T. O'Higgins, M. Lago, \& T. H. DeWitt (Eds.), Ecosystembased management, ecosystem services and aquatic biodiversity: Theory, tools and applications (pp. 39-60). Amsterdam: Springer.

DeWitt, T. H., Berry, W. J., Canfield, T. J., Fulford, R. S., Harwell, M. C., Hoffman, J. C., Johnston, J. M., Newcomer-Johnson, T. A., Ringold, P. L., Russel, M. J., Sharpe, L. A., \& Yee, S. J. H. (2020). The final ecosystem goods and services (FEGS) approach: A beneficiarycentric method to support ecosystem-based management. In T. O'Higgins, M. Lago, \& T. H. DeWitt (Eds.), Ecosystem-based management, ecosystem services and aquatic biodiversity: Theory, tools and applications (pp. 127-148). Amsterdam: Springer.

Farber, S. C., Costanza, R., \& Wilson, M. A. (2002). Economic and ecological concepts for valuing ecosystem services. Ecological Economics, 41(3), 4375-4392.

Finisdore, J., Rhodes, C., Haines-Young, R., Maynard, S., Wielgus, J., Dvarskas, A., Houdet, J., Quétier, F., Ding, H., Soulard, F., \& Van Houtven, G. (2019). Expanding the field of ecosystem services practitioners-18 benefits from using classification systems. Sustainable FlowsImproving Financial \& Ecosystem Services Flows. Retrieved October 9, 2019, from https:// www.researchgate.net/profile/John_Finisdore/publication/329402275_Expanding_the_field_ of_ecosystem_services_practitioners-18_benefits_from_using_classification_systems_Ver sion_11_March_2019/links/5c794e60458515831f7b2bec/Expanding-the-field-of-ecosystemservices-practitioners-18-benefits-from-using-classification-systems-Version-11-March-2019. pdf.

Foley, M. M., Armsby, M. H., Prahler, E. E., Caldwell, M. R., Erickson, A. L., Kittinger, J. N., Crowder, L. B., \& Levin, P. S. (2013). Improving ocean management through the use of ecological principles and integrated ecosystem assessments. BioScience, 63(8), 619-631.

Fu, B. J., Su, C. H., Wei, Y. P., Willett, I. R., Lü, Y. H., \& Liu, G. H. (2011). Double counting in ecosystem services valuation: Causes and countermeasures. Ecological Research, 26(1), 1-14.

Fulford, R. S., Heymans, S. J. J., \& Wu, W. (2020). Mathematical modelling for ecosystem-based management (EBM) and ecosystem goods and services (EGS) assessment. In T. O'Higgins, M. Lago, \& T. H. DeWitt (Eds.), Ecosystem-based management ecosystem services and aquatic biodiversity: Theory, tools and applications (pp. 275-290). Amsterdam: Springer.

Guerry, A. D., Polasky, S., Lubchenco, J., Chaplin-Kramer, R., Daily, G. C., Griffin, R., Ruckelshaus, M., Bateman, I. J., Duraiappah, A., Elmqvist, T., \& Feldman, M. W. (2015). Natural capital and ecosystem services informing decisions: From promise to practice. PNAS, $112(24), 7348-7355$.

Gundimeda, H., Sukhdev, P., Sinha, R. K., \& Sanyal, S. (2007). Natural resource accounting for Indian states-Illustrating the case of forest resources. Ecological Economics, 61(4), 635-649.

Hein, L., Bagstad, K., Edens, B., Obst, C., de Jong, R., \& Lesschen, J. P. (2016). Defining ecosystem assets for natural capital accounting. PLoS One, 11(11), e0164460.

Hoekstra, A. Y. (2009). Human appropriation of natural capital: A comparison of ecological footprint and water footprint analysis. Ecological Economics, 68(7), 1963-1974. 
Jewhurst, S., \& Mazzotta, M. (2016). Economic tools for managing nitrogen in coastal watersheds. EPA/600/R-16/036. U.S. Environmental Protection Agency.

Landers, D. H., \& Nahlik, A. M. (2013). Final Ecosystem Goods and Services Classification System (FEGS-CS). EPA/600/R-13/ORD-004914. U.S. Environmental Protection Agency.

Landers, D., Nahlik, A., \& Rhodes, C. R. (2016). The beneficiary perspective-Benefits and beyond. In M. Potchin, R. Haines-Young, R. Fish, \& K. Turner (Eds.), Routledge handbook of ecosystem services (pp. 74-87). New York: Routledge.

Lange, G. M. (2004). Wealth, natural capital, and sustainable development: Contrasting examples from Botswana and Namibia. Environmental and Resource Economics, 29(3), 257-283.

Lewis, N. S., Marois, D. E., Littles, C. J., \& Fulford, R. S. (2020). Projecting changes to coastal and estuarine ecosystem goods and services - models and tools. In T. O'Higgins, M. Lago, \& T. H. DeWitt (Eds.), Ecosystem-based management, ecosystem services and aquatic biodiversity: Theory, tools and applications (pp. 235-254). Amsterdam: Springer.

Millennium Ecosystem Assessment. (2005). Ecosystems and human well-being: Synthesis. Washington, DC: Island Press.

Piet, et al. (2017). Making ecosystem-based management operational: Deliverable 8.1 Executive Summary. Report as part of the Horizon 2020 project AQUACROSS (Knowledge, Assessment, and Management for AQUAtic Biodiversity and Ecosystem Services aCROSS EU policies). Retrieved October 9, 2019, from https://aquacross.eu/sites/default/files/AQUACROSS\% 20Executive\%20Summary\%20D8.1_v2_18062018.pdf.

United Nations. (2014). System of environmental-economic accounting 2012-Experimental ecosystem accounting. Retrieved October 9, 2019, from https://seea.un.org/sites/seea.un.org/files/ seea_eea_final_en_1.pdf.

United States. (2017). North American Industry Classification System manual. Retrieved October 9, 2019, from https://www.census.gov/eos/www/naics/2017NAICS/2017_NAICS_Manual.pdf.

United States Environmental Protection Agency (USEPA). (2015). National Ecosystem Services Classification System (NESCS): Framework design and policy application. EPA-800-R-15-002. U.S. Environmental Protection Agency.

Wackernagel, M., Onisto, L., Bello, P., Linares, A. C., López Falfán, I. S., Garcıa, J. M., Guerrero, A. I. S., \& Guerrero, M. G. S. (1999). National natural capital accounting with the ecological footprint concept. Ecological Economics, 29(3), 375-390.

Warnell, K., Russell, M., Rhodes, C., Bagstad, K., Olander, L., Nowak, D, Poudel, R., Glynn, P., Hass, J., Hirabayashi, S., Carter Ingram, J., Matuszak, J., Oleson, K., Posner, S., and Villa, F. (2020). Testing ecosystem accounting in the United States: A case study for the Southeast. Ecosystem Services, 43, https://doi.org/10.1016/j.ecoser.2020.101099.

Weber, J. L. (2007). Implementation of land and ecosystem accounts at the European Environment Agency. Ecological Economics, 61(4), 695-707.

Open Access This chapter is licensed under the terms of the Creative Commons Attribution 4.0 International License (http://creativecommons.org/licenses/by/4.0/), which permits use, sharing, adaptation, distribution and reproduction in any medium or format, as long as you give appropriate credit to the original author(s) and the source, provide a link to the Creative Commons licence and indicate if changes were made.

The images or other third party material in this chapter are included in the chapter's Creative Commons licence, unless indicated otherwise in a credit line to the material. If material is not included in the chapter's Creative Commons licence and your intended use is not permitted by statutory regulation or exceeds the permitted use, you will need to obtain permission directly from the copyright holder.

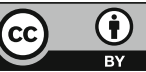

